\title{
Human Oral Mucosal Stem Cells Reduce Anastomotic Leak in an Animal Model of Colonic Surgery
}

\author{
Ilan Kent ${ }^{a, e} \quad$ Cyrus Jahansouz ${ }^{b}$ Amandeep Ghuman ${ }^{c}$ Baruch Shpitz ${ }^{\mathrm{e}}$ \\ Debora Kidron $^{d, e}$ Victoria Yaffe ${ }^{f}$ Imad Abu El-Naaj ${ }^{f}$ Shareef Araidy ${ }^{f}$ \\ Luciana Reina $^{\mathrm{e}}$ Sandu Pitarug Steven David Wexner ${ }^{\mathrm{h}}$ Shmuel Avital ${ }^{\mathrm{a}}$ e \\ ${ }^{a}$ Department of Surgery, Meir Medical Center, Kfar Saba, Israel; ${ }^{b}$ Division of Colon and Rectal Surgery, Department

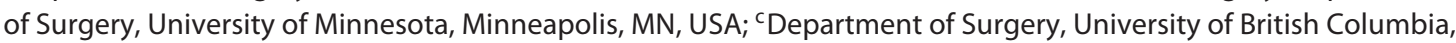 \\ Vancouver, BC, Canada; ${ }^{d}$ Department of Pathology, Meir Medical Center, Kfar Saba, Israel; ${ }^{e}$ Faculty of Medicine, Tel

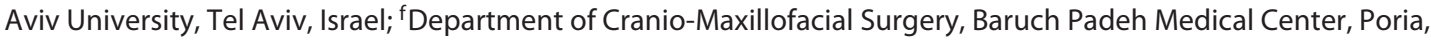 \\ Israel; ${ }^{9}$ Department of Oral Biology, School of Dental Medicine, Faculty of Medicine, Tel Aviv University, Tel Aviv,

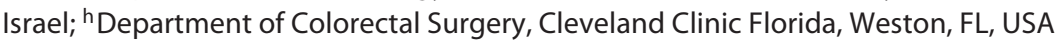

\section{Keywords}

Stem cells · Anastomotic leak · Colon surgery

\begin{abstract}
Background: Anastomotic leak is regarded as one of the most feared complications of bowel surgery; avoiding leaks is a major priority. Attempts to reduce or eliminate leaks have included alternate anastomotic techniques. Human oral mucosa stem cells (hOMSC) are self-renewing and expandable cells derived from buccal mucosa. Studies have shown that hOMSC can accelerate tissue regeneration and wound healing. The objective of this study was to evaluate whether hOMSC can decrease anastomotic leak rates in a murine model of colon surgery. Methods: Two experiments were performed. In the first study, mice underwent colonic anastomosis using five interrupted sutures. hOMSC $(n=7)$ or normal saline (NS; $n=17$ ) was injected into the colon wall at the site of the anastomosis. To evaluate whether hOMSC can impact anastomotic healing, the model was stressed by repeating the first experiment, reducing the number of sutures used for the construction of the anastomosis from five to four. Either hOMSC $(n=8)$ or NS $(n=20)$ was injected at the
\end{abstract}

anastomosis. All mice that survived were sacrificed on postoperative day 7. Anastomotic leak rate, mortality, daily weight, and daily wellness scores were compared. Results: In the five-suture anastomosis, there were no differences in anastomotic leak rate, mortality, or daily weight. Mice that received hOMSC had significantly higher wellness scores on postoperative day $2(p<0.05)$. In the four-suture anastomosis, there was a significant decrease in leak rate $(70 \%$ [NS] vs. $25 \%$ [hOMSC], $p=0.029$ ) and higher wellness scores in mice that received hOMSC $(p<0.05)$. Conclusion: Our study suggests that injecting hOMSC at the colonic anastomosis can potentially reduce anastomotic leak and improve postoperative wellness in a murine model of colon surgery.

(c) 2021 S. Karger AG, Basel

\section{Introduction}

Anastomotic leak is regarded as one the most feared complications in bowel surgery [1]. The rate of clinically apparent anastomotic leakage is reported to be as high as $19 \%$ [2]. This complication greatly increases morbidity including invasive interventions, reoperation, prolonged 
hospitalization, and death. As many as one-third of deaths following colorectal surgery are attributed to anastomotic leakage [3]. Known risk factors for anastomotic leaks are patient factors such as age and comorbidities, as well as surgical technique and anastomotic indication and location $[4,5]$. Considering the immense burden of leaks on the patient, surgeon, and health care system [6], there is a critical need to identify techniques to prevent colonic anastomotic dehiscence.

One of the newer fields of medicine involves the utilization of stem cells in the regeneration of tissue. These cells can differentiate into various types of cells and divide indefinitely to produce more of the same stem cells, and they also have the capacity to differentiate into specialized cell types. Different cell lineages such as induced pluripotent stem cells, embryogenic stem cells, bone marrowderived stem cells, and mesenchymal stem cells have different prospective applications and vary in their harvesting potential, which may limit their clinical utility.

Human oral mucosa stem cells (hOMSC) are a novel stem cell population obtained from the lamina propria of the buccal mucosa; they are of primitive neural crest origin and have been shown to differentiate into all three germ layers in vitro [7]. These cells lack HLA antigen and have been shown to display immunosuppressive effects through mediating apoptosis of host $\mathrm{T}$ cells and generating immunosuppressive regulatory $\mathrm{T}$ cells [8]; thus, they are not anticipated to induce a robust immunogenic response. hOMSC have unique characteristics that potentially provide them with an advantage over other stem cell lines: they are easy to donate as well as to harvest, exhibit similar characteristics when isolated from donors regardless of age, and produce a viable stable culture allowing the production of a large number of cells from a small biopsy. Of interest, they have been proposed to play a crucial role in regeneration of tissues such as rapid wound healing of the oral mucosa, increase wound healing in a diabetic mouse model [9], and have a positive effect on spinal cord injured mice [10].

Animal studies have examined the effects of adipose tissue and bone marrow-derived stem cells on bowel anastomosis healing and have previously shown that treatment with stem cells confers significant improvement in healing, resulting in reduced leak rates and increased survival [11-13]. To the best of our knowledge, the potential of hOMSC to improve anastomotic healing has not been evaluated. The objective of this study was to investigate whether hOMSC injected at the site of an anastomosis can reduce dehiscence and leak rates in a murine model of colon anastomosis (Fig. 1).

\section{Methods}

\section{Animals}

Full-grown ( $>35 \mathrm{~g}$ ) C57BL/6 mice were used in this study. The study protocol was approved by the animal Ethics Committee at Rabin Medical Center and the Israeli Ministry of Health (protocol No. 022-b13400-010318). The mice were randomly chosen from a cage housing similarly aged mice, purchased from Envigo Labs, Ness Ziona, Israel. Each mouse was assessed using a wellness score prior to the experiment. Any animal exhibiting less than a perfect score of 12 was excluded throughout the entire study.

\section{Human Oral Mucosa Stem Cells}

hOMSC were generated as described by Marynka-Kalmani et al. [14]. Oral mucosa biopsies were obtained from donors following study approval by the Institutional Helsinki Committee of Baruch Padeh Medical Center, Poria, Israel (study protocol No. 20162053). The donors consented to the use of stem cells generated from oral mucosa biopsies for research purposes in animal models. Briefly, cells were harvested from oral mucosa biopsies of gingival mucosa obtained from the human donors. The gingival biopsies were incubated overnight at $4^{\circ} \mathrm{C}$ in dispase. The epithelial layer was then separated from the lamina propria and was minced into pieces and placed in 35-mm culture dishes. Expansion medium consisting of low-glucose Dulbecco's modified Eagle's medium and $10 \%$ fetal calf serum with antibiotics was added to the explants to enhance their attachment to the floor of the dish. Cells that migrated from the explant to the culture dishes were harvested with $0.25 \%$ trypsin and further expanded at a cell density of $4 \times$ $10^{4}$ cells $/ \mathrm{cm}^{2}$ in culture dishes.

\section{Study Design and Operation}

Two experiments were performed. In the first experiment, all mice were subjected to a leak model as previously described [15]. The procedure consisted of anesthetizing the mouse (intramuscular injection of ketamine hydrochloride $50-100 \mathrm{mg} / \mathrm{kg}$ of body weight) and disinfecting the abdomen. Thereafter, the abdomen was entered through a $2-\mathrm{cm}$ midline incision. The colon was transected $1 \mathrm{~cm}$ distal to the cecum, after which an end-to-end anastomosis was constructed with five interrupted sutures (Fig. 2; PDS 6-0; Ethicon Inc., Somerville, NJ, USA). Using a Hamilton glass syringe fitted with a $22-\mathrm{G}$ needle with a $45^{\circ}$ bevel (Hamilton Inc., Reno, NV, USA), the colon was injected $1 \mathrm{~mm}$ proximal and $1 \mathrm{~mm}$ distal to the anastomotic site with either $50 \mu \mathrm{L}$ of phosphate-buffered saline medium containing 400,000 hOMSC or $50 \mu \mathrm{L}$ of normal saline (NS). Five microliters (roughly 40,000 hOMSC in the experiment group) were injected circumferentially at five points proximal and at five points distal to the anastomosis. The contents were injected at a level of depth through the serosa into the mucosal layer of the bowel. The colon was then repositioned within the abdomen and the abdominal wall was closed in two layers (Vicryl 5-0; Ethicon Inc.). All intraabdominal manipulations were performed with surgical loupes $(2.5 \mathrm{X})$ to ensure optimal visualization.

The animals were closely monitored on a daily basis for the duration of the experiment, with daily measurements of weight and calculation of wellness scores (online suppl. Table 1; for all online suppl. material, see www.karger.com/doi/10.1159/000514987). The wellness score was used as it has previously been shown to correlate with anastomotic leakage, with lower scores being consistent with a higher rate of leakage [15]. Necropsy was performed on all 


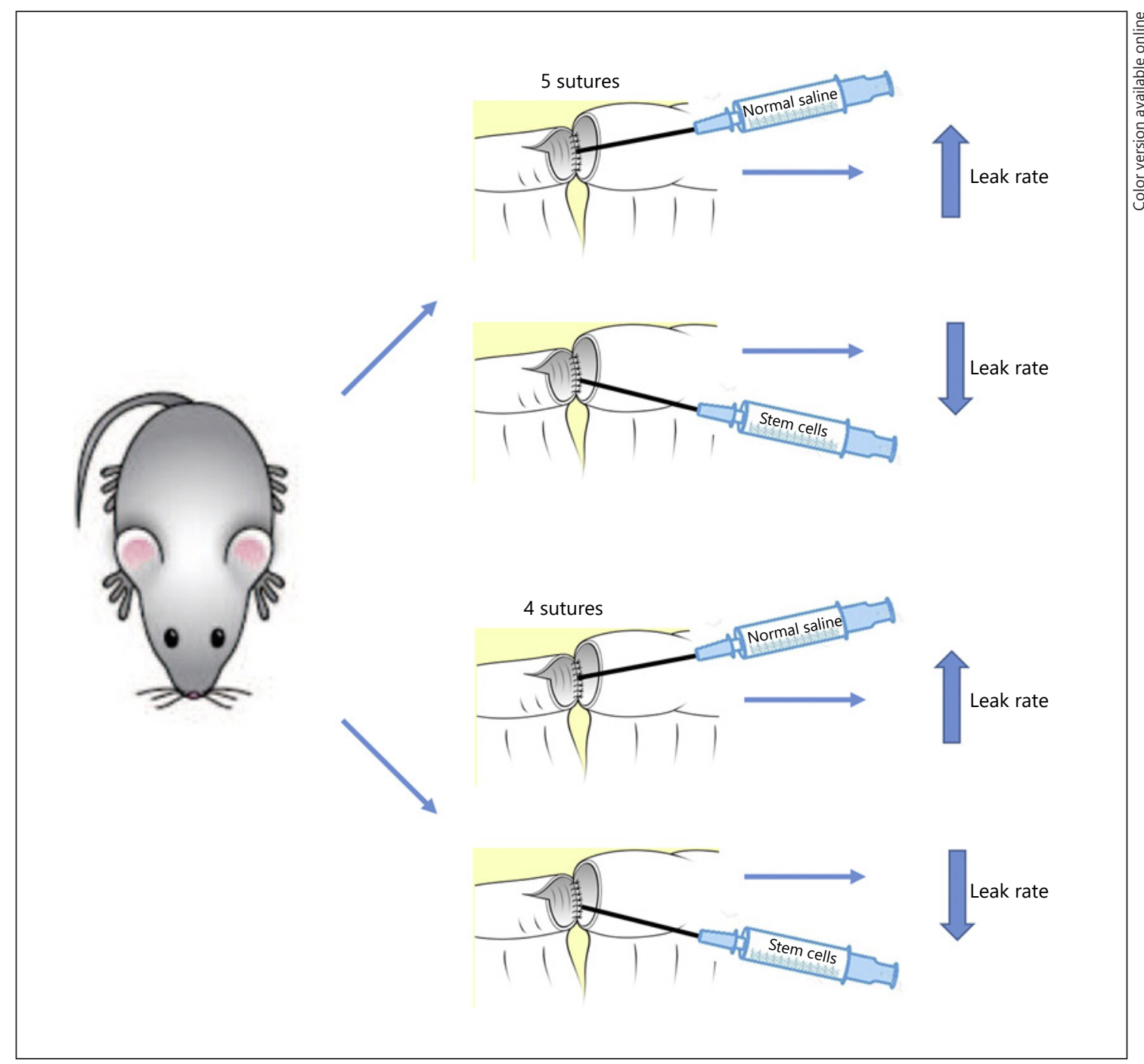

Fig. 1. Study design and hypothesis. Two experiments were performed. In the first experiment, the colon was transected and an anastomosis was performed with five sutures. The mice were injected with either normal saline or human oral mucosa stem cells (hOMSC) at the anastomosis. The second experiment repeated the first experiment with the exception of the creation of a colon

animals either at the time of death or following euthanasia on postoperative day 7. Necropsies that were performed prior to the end of the study period were confirmed to show feculent peritonitis. The abdominal cavity was examined by a trained colorectal surgeon (I.K.), who was blinded to the treatment group, for evaluation of anastomotic leakage as defined by either feculent peritonitis or perianastomotic abscess formation. Anastomotic leaks were recorded. A 3-cm segment of the colon and associated mesentery including the anastomosis were completely dissected for histopathological investigation. All aspects of the second experiment were identical to those of the first experiment, with the exception of the construction of the colonic anastomosis, which was undertaken with only four sutures. anastomosis with four sutures. All mice were sacrificed on postoperative day 7 , at which time each mouse was evaluated for the presence of anastomotic dehiscence. Daily weights were measured and wellness scores were calculated. We predicted that mice receiving hOMSC would have a reduction in the rate of anastomotic leaks.

\section{Histopathological Examination}

The histological characteristics of the healing anastomosis were assessed by a certified pathologist. Following necropsy, the anastomosis was excised together with $1 \mathrm{~cm}$ of the adjacent proximal and distal colon margins. The tissues were fixed in $10 \%$ formalin for approximately $24 \mathrm{~h}$. Transverse sections through the anastomosis site were submitted for histology. The tissues underwent routine histologic processing and were embedded in paraffin and sliced into 4 - $\mu \mathrm{m}$-thick sections. The sections were stained with $\mathrm{H} \& \mathrm{E}$ (hematoxylin and eosin) and Masson trichrome. The sites of anastomosis were evaluated for signs of inflammation and healing. The following histologic features were recorded: anatomic integrity of the bowel wall; bowel contents outside of the lumen; and the 

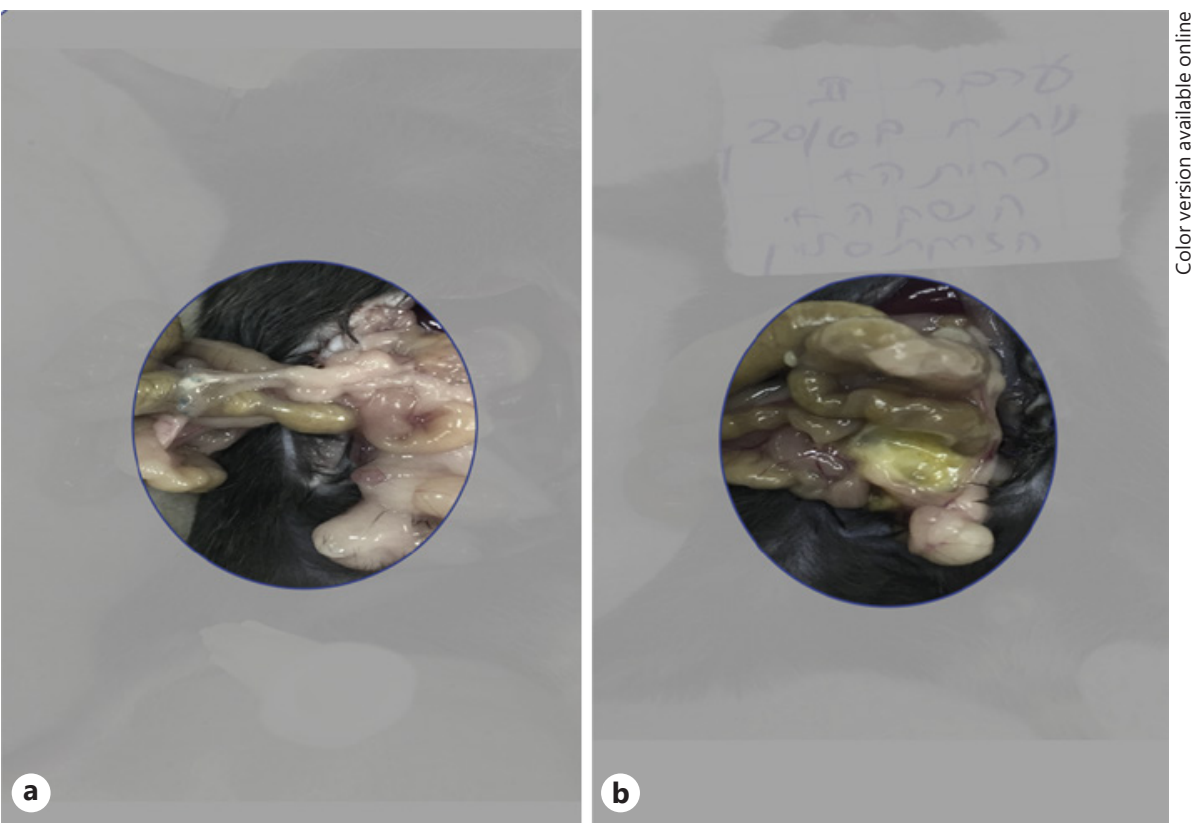

Fig. 2. a Well-healed colonic anastomosis. b Anastomosis with evidence of abscess formation.
$70.5 \%$ [NS] vs. $71.4 \%$ [hOMSC]; $p=0.61$ ). Weights were not statistically significantly different on any of the postoperative days (Fig. 3c). Wellness scores (Fig. 3d) were also evaluated in all surviving mice, and they were significantly higher on postoperative day 2 in the hOMSC cohort (11.7 \pm 0.2 vs. $10.0 \pm 0.4 ; p<0.05)$.

\section{Experiment 2: Stem Cells Reduce Leak Rates in a \\ Four-Suture Colon Anastomosis}

To evaluate whether hOMSC impacted anastomotic healing, the model was stressed by reducing the number of sutures used for the construction of the anastomosis from five to four in 28 mice (NS, $n=20$; hOMSC, $n=8$ ). In the NS cohort, $70 \%(n=14)$ of the mice had evidence of either feculent peritonitis or abscess formation, versus $25 \%(n=2)$ of the mice that received hOMSC ( $p=0.029$; Fig. 4a). Through the 7-day period, the survival rate was $55 \%$ in the NS $(n=11)$ cohort versus $37.5 \%(n=3)$ in the hOMSC cohort ( $p=0.11$; Fig. $4 b)$. Weight assessment was performed on all surviving mice; no statistically significant differences were identified (Fig. 4c). Wellness scores were significantly higher in the hOMSC cohort on postoperative days $1(11.8 \pm 0.2$ [hOMSC] vs. $10.7 \pm 0.2$ [NS]; $p<0.05)$ and $3(11.8 \pm 0.2$ [hOMSC] vs. $10.6 \pm 0.4$ [NS]; $p<0.05)$ relative to the NS cohort (Fig. $4 \mathrm{~d}$ ).

\section{Histopathology}

Anastomotic leakage was diagnosed when bowel disruption, abscess formation, or heavy leukocyte infiltra- 


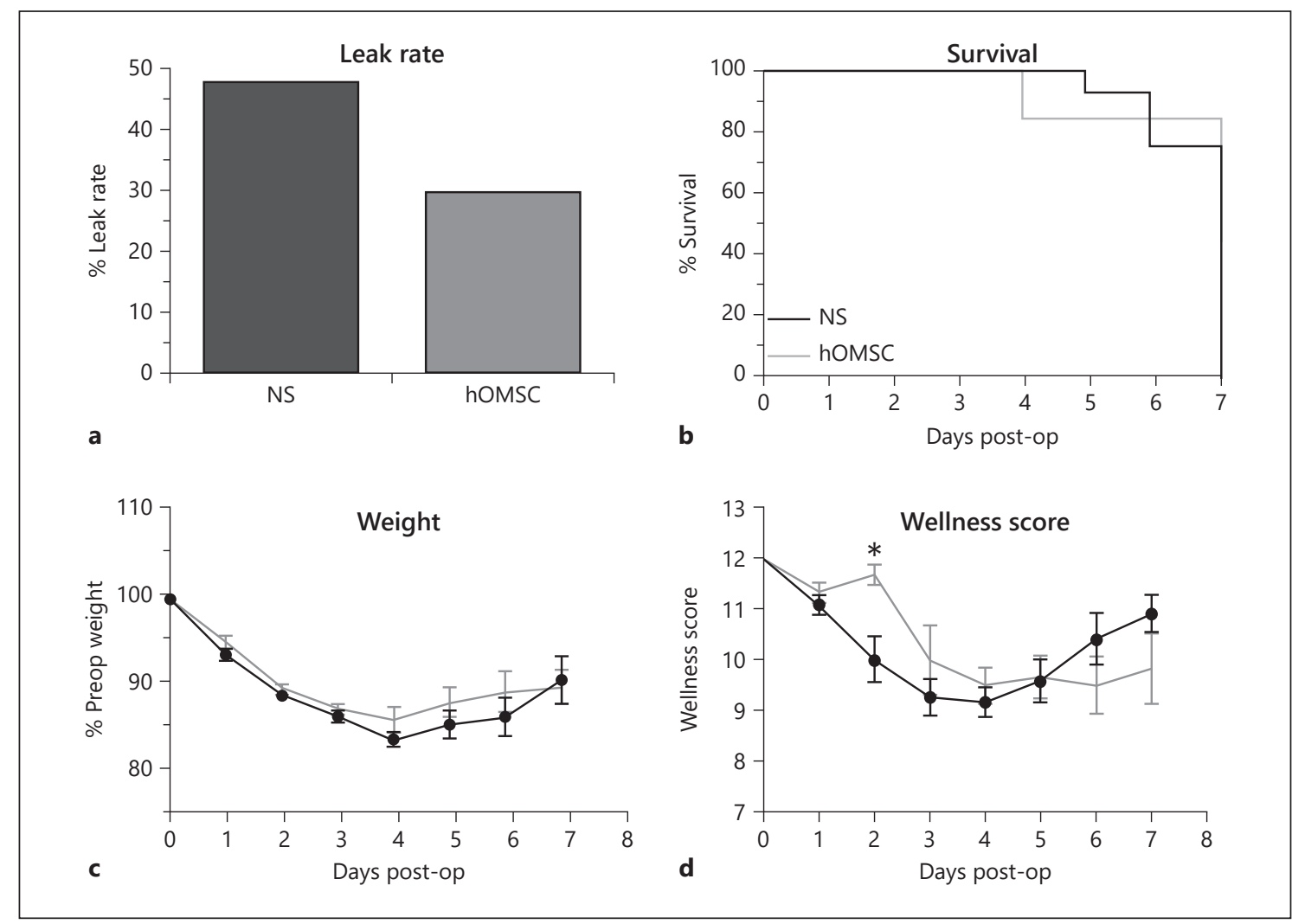

Fig. 3. Five-suture colonic anastomosis ( $\mathrm{NS}=17$, hOMSC $=7$ ). a Leak rate. b Survival. c Daily weight evaluation. d Daily wellness score. NS, normal saline; hOMSC, human oral mucosa stem cells.

tion was present. No obvious differences in histologic features of anastomotic leakage, perforation, necrosis of the bowel wall, or healing were noted between anastomoses treated with hOMSC (online suppl. Fig. 1) and those injected with NS (online suppl. Fig. 2). No hOMSC were identifiable by $H \& E$ staining in any histologic section, and we suspect that this is due to the lack of more sophisticated techniques, such as immunohistochemistry or confocal microscopy, rather than hOMSC demise.

\section{Discussion}

Anastomotic dehiscence is a major complication that results in devastating consequences. Such a costly event not only negatively impacts functional outcomes, but also increases the risk of cancer recurrence, morbidity, and mortality [16-18]. The introduction of stem cells into the environment of a new bowel anastomosis is a novel approach to reduce the risk of dehiscence. Here, we showed that transplanting hOMSC to a faulty colonic anastomo- sis decreased the rate of anastomotic leaks in a murine model and resulted in improved overall wellness scores in the early postoperative period.

hOMSC are a novel line of stem cells produced from human oral tissue, and they have been shown to differentiate into all three germ layers in vitro. Cells are harvested from the oral buccal mucosa, making them readily accessible and easy to harvest. Furthermore, given the potent healing capacity of the buccal mucosa, the impact from harvesting is minimal, providing for rapid recovery. These factors make this procedure particularly advantageous when compared to harvesting of other stem cells derived from bone marrow and mesenchymal adipose tissue. hOMSC are produced relatively quickly in culture media, and a small biopsy is sufficient to produce trillions of stem cells [7]. Furthermore, they exhibit similar characteristics when isolated from young or old donors and are minimally affected by advanced passages [14]. The potential of these cells to promote anastomotic healing may be mediated by cellular and noncellular factors. hOMSC have been shown to differentiate into a multi- 


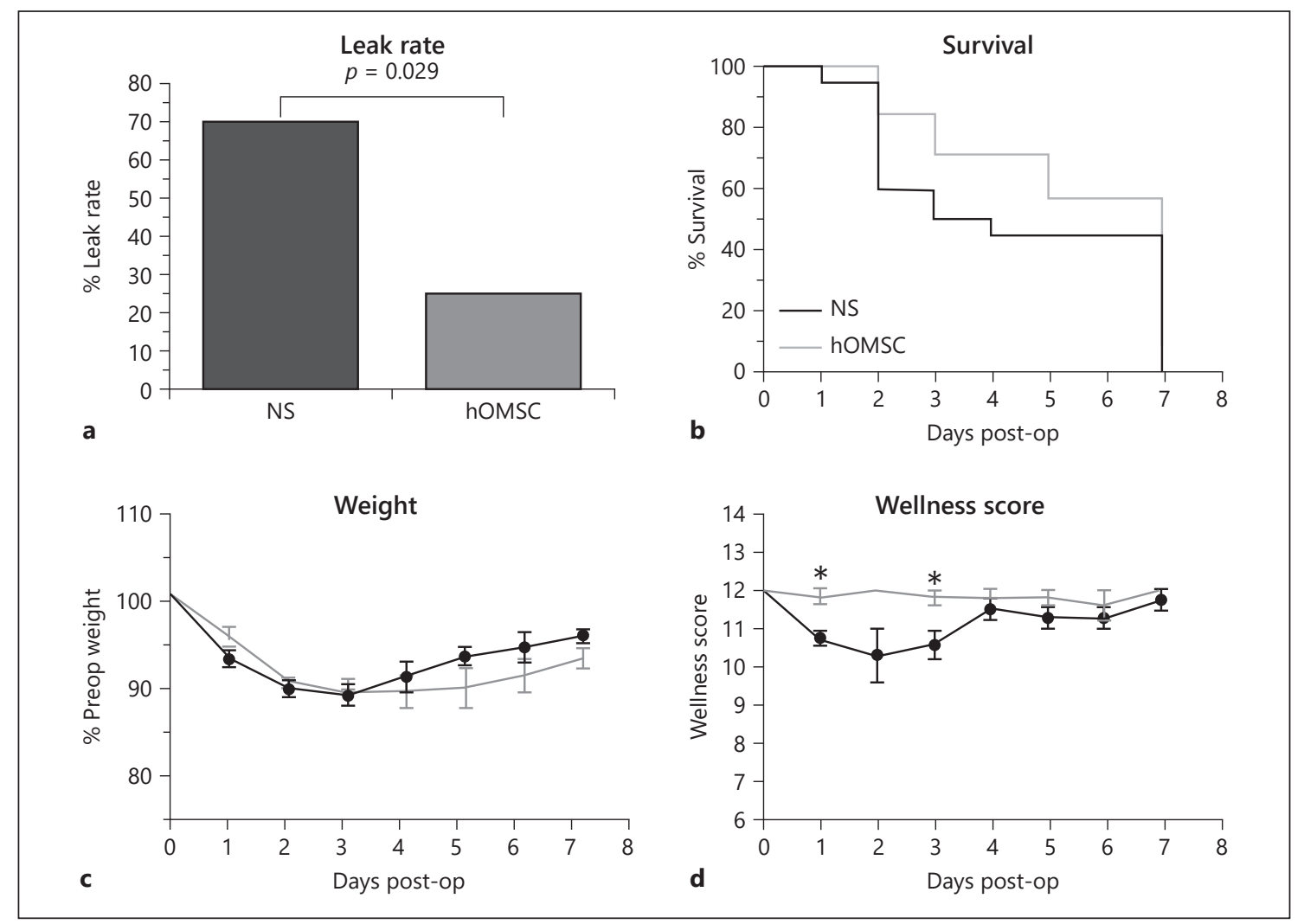

Fig. 4. Four-suture colonic anastomosis (NS = 20, hOMSC $=8$ ). a Leak rate. b Survival. c Daily weight evaluation. d Daily wellness score. NS, normal saline; hOMSC, human oral mucosa stem cells.

tude of cell types upon exposure to environmental signals [19] and to also produce and secrete growth factors such as FGF-2, EGF, VEGF, and NGF [14].

In this study, we postulated that the application of hOMSC to a newly created anastomosis would reduce the rate of anastomotic dehiscence. In order to test this hypothesis, we initially constructed a colonic anastomosis with five interrupted sutures. Although we did not identify a difference in the rate of anastomotic leaks, interestingly we identified a higher wellness score early following surgery. Mice exhibit faster metabolism and show clinical signs of leakage earlier than expected in humans, which explains lower wellness scores early following surgery. When considering that all animals undergoing colon resection and construction of a faulty anastomosis using only five sutures had a leaking anastomosis, higher wellness scores early postoperatively might demonstrate the enhanced efficacy of hOMSC in promoting anastomotic healing in mice injected with stem cells. To further test our hypothesis, we repeated the experiment constructing the anastomosis with four sutures in an attempt to evalu- ate the extent to which the application of hOMSC may overcome significant mechanical disruption. While it is recognized that blood flow to the healing anastomosis is critical to reduce the risk of leakage, this model is unique in that it imitates a mechanically disrupted and faulty anastomosis independent of blood supply. In doing so, we found that the application of hOMSC decreased anastomotic leak rates and increased wellness scores.

Our results are consistent with previously published work showing reduced anastomotic leakage with the application of stem cells. Adas et al. [11] found that the use of mesenchymal stem cells harvested from bone marrow enhanced the recovery of an ischemic colonic anastomosis in a rat model. Yoo et al. [20] showed that transplanting adipose tissue-derived stem cells supports anastomotic healing by promoting angiogenesis, resulting in a decrease in leak rates and an increase in bursting pressure. Furthermore, Maruya et al. [12] found that transplantation of autologous adipose-derived stem cells enhanced collagen synthesis and anastomotic strength in pigs treated with a fibroblast proliferation-inhibiting agent (MMC). Notably, we also identi- 
fied a common theme, namely that if mice survived, those that received hOMSC consistently displayed higher wellness scores early in the postoperative period independently of how the anastomosis was constructed.

There are important limitations in our study. While the intent of our study was to evaluate the impact of hOMSC on anastomotic leakage and animal well-being, our study lacks mechanistic investigations underlying the activity of hOMSC. Previous studies have suggested that hOMSC may contribute to wound healing, reepithelialization, and deposition of granulation tissue by promoting cellular differentiation, immunomodulation via the recruitment of different immune cell populations, and production of growth factors that further enable the recruitment of resident local stem cells [21]. More studies are required to fully elucidate these mechanisms, and they may include gene expression analysis and tissue collagenase activity. Additionally, we did not quantify the immune cell populations on histopathology, which may be performed by image morphological analysis as previously described [22]. Burst pressure evaluation of the anastomoses was not performed in this pilot study as well. These important aspects will be the focus of our future studies. Furthermore, we recognize a difference in sample size as a limitation. A component of this study was to perform model development and evaluate outcomes with four-suture and five-suture colocolonic anastomoses. Thus, more mice were selected for the control arms to evaluate a baseline anastomotic leak rate within each of these arms.

To the best of our knowledge, this is the first study to identify the potential role for hOMSC in reducing anastomotic leakage and improve postoperative wellness. Further studies are needed to elucidate the true potential of these cells in preventing anastomotic dehiscence and their translational capacity to the clinical setting. The successful utilization of stem cells can further open a new avenue in surgical research with the goals of improving tissue healing and regeneration and, ultimately, patient outcomes.

\section{Acknowledgements}

The authors would like to thank Mrs. Dalia Sela for her assistance with animal welfare. We would like to acknowledge her endless dedication over the past four decades while aiding, guiding, instructing, and teaching hundreds of students on the science of animal research.

\section{Statement of Ethics}

The study protocol was approved by the animal Ethics Committee at Rabin Medical Center and the Israeli Ministry of Health (protocol No. 022-b13400-010318). Oral mucosa biopsies were obtained from donors following study approval by the Institutional Helsinki committee of Baruch Padeh Medical Center, Poria, Israel (study protocol No. 20162053). The donors consented to the use of stem cells generated from their oral mucosa biopsies for research purposes in animal models.

\section{Conflict of Interest Statement}

I.K., C.J., A.G., B.S., D.K., V.Y., I.A.E.-N., S.A., L.R., S.D.W., and S.A. report no proprietary or commercial interest in any product mentioned or concept discussed in this article. S.P. holds equities in Cytora, and he is the chief scientist of Cytora Ltd.

\section{Funding Sources}

This research did not receive any specific grant from funding agencies in the public, commercial, or not-for-profit sectors.

\section{Author Contributions}

I.K., C.J., B.S., S.P., S.D.W., and S.A. study conception and design. I.K., B.S., and L.R. conduction of animal lab experiments. I.A.E.-N., S.A., and V.Y. harvesting and cultivation of HOMSC. I.K., C.J., and A.G. data gathering and analysis. D.K. histology evaluation. I.K., C.J., and A.G. drafting of manuscript. I.K., C.J., A.G., S.D.W., and S.A. critical revision of manuscript.

\section{References}

1 Hyman NH. Managing anastomotic leaks from intestinal anastomoses. Surgeon. 2009 Feb;7(1):31-5.

2 McDermott FD, Heeney A, Kelly ME, Steele RJ, Carlson GL, Winter DC. Systematic review of preoperative, intraoperative and postoperative risk factors for colorectal anastomotic leaks. Br J Surg. 2015 Apr; 102(5):46279.

3 Egger B, Inglin R, Zeeh J, Dirsch O, Huang Y, Büchler MW. Insulin-like growth factor I and truncated keratinocyte growth factor acceler- ate healing of left-sided colonic anastomoses. Br J Surg. 2001 Jan;88(1):90-8.

4 Trencheva K, Morrissey KP, Wells M, Mancuso CA, Lee SW, Sonoda T, et al. Identifying important predictors for anastomotic leak after colon and rectal resection: prospective study on 616 patients. Ann Surg. 2013 Jan; 257(1):108-13.

5 Pommergaard HC, Gessler B, Burcharth J, Angenete E, Haglind E, Rosenberg J. Preoperative risk factors for anastomotic leakage after resection for colorectal cancer: a system- atic review and meta-analysis. Colorectal Dis. 2014 Sep;16(9):662-71.

6 Koperna T. Cost-effectiveness of defunctioning stomas in low anterior resections for rectal cancer: a call for benchmarking. Arch Surg. 2003 Dec;138(12):1334-8.

7 Treves-Manusevitz S, Hoz L, Rachima H, Montoya G, Tzur E, Vardimon A, et al. Stem cells of the lamina propria of human oral mucosa and gingiva develop into mineralized tissues in vivo. J Clin Periodontol. 2013 Jan; 40(1):73-81. 
8 Akiyama K, Chen C, Wang D, Xu X, Qu C, Yamaza T, et al. Mesenchymal-stem-cell-induced immunoregulation involves FAS-ligand-/FAS-mediated T cell apoptosis. Cell Stem Cell. 2012 May;10(5):544-55.

9 Kuperman S, Efraty R, Arie I, Rahmanov A, Rahmanov Gavrielov M, Noff M, et al. Examination of the Therapeutic Potential of Mouse Oral Mucosa Stem Cells in a Wound-Healing Diabetic Mice Model. Int J Environ Res Public Health. 2020 Jul;17(13):E4854.

10 Ganz J, Shor E, Guo S, Sheinin A, Arie I, Michaelevski I, et al. Implantation of 3D constructs embedded with oral mucosa-derived cells induces functional recovery in rats with complete spinal cord transection. Front Neurosci. 2017 Oct;11(OCT):589.

11 Adas G, Arikan S, Karatepe O, Kemik O, Ayhan S, Karaoz E, et al. Mesenchymal stem cells improve the healing of ischemic colonic anastomoses (experimental study). Langenbecks Arch Surg. 2011 Jan;396(1):115-26.

12 Maruya Y, Kanai N, Kobayashi S, Koshino K, Okano T, Eguchi S, et al. Autologous adiposederived stem cell sheets enhance the strength of intestinal anastomosis. Regen Ther. 2017 Jul; 7:24-33.
13 Morgan A, Zheng A, Linden KM, Zhang P, Brown SA, Carpenter JP, et al. Locally Transplanted Adipose Stem Cells Reduce Anastomotic Leaks in Ischemic Colorectal Anastomoses: A Rat Model. Dis Colon Rectum. 2020 Jul;63(7):955-64.

14 Marynka-Kalmani K, Treves S, Yafee M, Rachima H, Gafni Y, Cohen MA, et al. The lamina propria of adult human oral mucosa harbors a novel stem cell population. Stem Cells. 2010 May;28(5):984-95.

15 Komen N, van der Wal HC, Ditzel M, Kleinrensink GJ, Jeekel H, Lange JF. Colorectal anastomotic leakage: a new experimental model. J Surg Res. 2009 Jul;155(1):7-12.

16 Sarcher T, Dupont B, Alves A, Menahem B. Anterior resection syndrome: what should we tell practitioners and patients in 2018? J Visc Surg. 2018 Oct;155(5):383-91.

17 Allaix ME, Rebecchi F, Famiglietti F, Arolfo S, Arezzo A, Morino M. Long-term oncologic outcomes following anastomotic leak after anterior resection for rectal cancer: does the leak severity matter? Surg Endosc. 2020 Sep; 34(9):4166-76.
18 Yang J, Chen Q, Jindou L, Cheng Y. The influence of anastomotic leakage for rectal cancer oncologic outcome: a systematic review and meta-analysis. J Surg Oncol. 2020 Jun;121(8): 1283-97.

19 Ganz J, Arie I, Ben-Zur T, Dadon-Nachum M, Pour S, Araidy S, et al. Astrocyte-like cells derived from human oral mucosa stem cells provide neuroprotection in vitro and in vivo. Stem Cells Transl Med. 2014 Mar;3(3):37586.

20 Yoo JH, Shin JH, An MS, Ha TK, Kim KH, Bae $\mathrm{KB}$, et al. Adipose-Tissue-Derived Stem Cells Enhance the Healing of Ischemic Colonic Anastomoses: An Experimental Study in Rats. J Korean Soc Coloproctol. 2012 Jun;28(3): 132-9.

21 Balaji S, Keswani SG, Crombleholme TM. The Role of Mesenchymal Stem Cells in the Regenerative Wound Healing Phenotype. Adv Wound Care (New Rochelle). 2012 Aug; 1(4):159-65.

22 Berho M, Wexner SD, Botero-Anug AM, Pelled D, Fleshman JW. Histopathologic advantages of compression ring anastomosis healing as compared with stapled anastomosis in a porcine model: a blinded comparative study. Dis Colon Rectum. 2014 Apr;57(4): 506-13. 